\title{
The effects of smokeless tobacco (oral snuff) on dynamic visual acuity
}

\author{
GERALD M. LONG and MIKE D. JONES \\ Villanova University, Villanova, Pennsylvania
}

\begin{abstract}
The effects of the use of smokeless tobacco (oral snuff) on observers' ability to resolve moving targets were assessed under four levels of target velocity for both light and heavy tobacco users among college students. Each observer was tested in several sessions, half immediately following the use of tobacco and half with no preceding tobacco use. No differences were found across the two types of sessions for any of the velocity conditions. The results are discussed in terms of the practical consequences of nicotine nystagmus reported by previous investigators.
\end{abstract}

Dynamic visual acuity (DVA) refers to an observer's ability to resolve fine detail in an object when there is relative motion between the observer and that object. The original interest in DVA can be traced to the work of Ludvigh and Miller in the late 1940s (see reviews by Miller \& Ludvigh, 1962, and Morrison, 1980). Two primary reasons have been cited for the continued attention paid to DVA. First, many real-world activities, including driving, flying, sports, and video games, typically require observers to detect, track, and resolve rapidly moving targets. Second, the relationship between DVA and traditional acuity is modest at best and declines drastically as target velocity exceeds even modest levels; hence, it is believed that traditional visual measures cannot assess this important visual ability (cf., Burg, 1966; Burg \& Hulbert, 1961; Fergenson \& Suzansky, 1973; Long \& May, 1992). Given these findings, the Committee on Vision of the National Research Council (1985) concluded that DVA represents an "emergent technique" that holds strong promise for improved visual assessment.

Much of the empirical work with DVA has involved the effect of various stimulus conditions on DVA performance. These have included target velocity, target illumination, target duration, target background, target wavelength, and target composition (e.g., Fergenson \& Suzansky, 1973; Long \& Garvey, 1988a, 1988b). However, given the apparent relevance of DVA for real-world tasks, many investigators have concerned themselves with practical aspects of DVA. Some have attempted to establish a direct relationship between DVA performance and specific tasks such as driving (Hulbert, Burg, Knoll, \& Mathewson, 1958), flying (DeKlerk, Eernst, \& Hoogerheide, 1964), and sports (Falkowitz \& Mendel, 1977). Others have focused on particular issues that are of obvious relevance for applied settings. For example, Burg (1966) and Long and Crambert (1990) examined the effect of age on DVA, with specific consideration of natural aging effects on daily activities involving moving tar-

Reprint requests should be sent to G. M. Long, Department of Psychology, Villanova University, Villanova, PA 19085. gets (e.g., driving). Ludvigh and Miller (1954) and Long and Rourke (1989) investigated the effectiveness of training on DVA performance.

Of direct relevance for the present work, some investigators have been concerned with the effect of commonly used substances such as alcohol, tobacco, and marijuana on DVA (Brown, Adams, Haegerstrom-Portnoy, Jones, \& Flom, 1975; Garvey, Goebel, Tyrrell, \& Gish, 1988; Long \& Franklin, 1989). Long and Franklin determined DVA performance in smokers immediately following the smoking of a cigarette. The impetus for their work was the recent finding that cigarette smoking produces a brief alteration in normal eye movement activity (Sibony, Evinger, \& Manning, 1987a, 1987b). For a 10- to 15min period after smoking, a vertical nystagmus is observed, and these vertical "jumps" are superimposed on any horizontal tracking movements. Long and Franklin hypothesized that the extraneous eye movements engendered by the smoking might prove detrimental on a standard DVA task. However, in their work they found no effect of the smoking for either light or heavy smokers under any of the dynamic target conditions. Long and Franklin concluded that, within the precision of measurement available to them, DVA was unaffected by tobacco smoking and would likely have little effect on any tracking performance in an applied setting.

The purpose of the present work was to determine the effects of tobacco on DVA performance, but under stronger conditions of nicotine uptake by the system. Specifically, we sought to assess the effects of smokeless tobacco (oral snuff) on DVA. Such an undertaking was thought to be justified by several considerations. First, it has been determined that smokeless tobacco produces higher concentrations of nicotine in the blood and that these concentrations remain for appreciably longer periods than those produced by cigarette smoking (e.g., Benowitz, Porchet, Sheiner, \& Jacob, 1988). This would allow us to test for nicotine effects under stronger (but still realistic) conditions of the drug, and we would be able to employ 30 - to 40 -min sessions rather than the abbreviated 12-min testing periods used by Long and Franklin. Second, smokeless tobacco has 
been reported to be quite popular among high school and college students, particularly among student athletes (e.g., Surgeon General's Report, 1986). Moreover, unlike cigarettes, smokeless tobacco is often used while the individual is directly engaged in the sport activity (e.g., baseball). The implications of demonstrating a detrimental effect of smokeless tobacco on DVA would be considerable.

\section{METHOD}

\section{Subjects}

Six male students at Villanova University who were users of smokeless tobacco were recruited as paid volunteers for this study. Each subject was paid at the rate of $\$ 7.50 / \mathrm{h}$ and was run in seven 40 - to 60 -min sessions. Prior to participating, each subject's static acuity was determined with a Titmus II Vision Tester (Titmus Corporation), which provided five steps in the acuity range between $20 / 20$ and $20 / 13$. The right-eye acuity for the 6 subjects was: 20/13, 20/15 (corrected), 20/15, 20/15, $20 / 17$, and $20 / 20$. Hence, the static acuity of the observers was uniformly excellent and varied over a very limited range.

On the basis of each observer's self report, they were designated as either "light" or "heavy" users of oral snuff. The 3 light users tended to take a "dip" 3-4 times per day, whereas the 3 heavy users tended to take a dip 7-8 times per day.

\section{Apparatus and Stimuli}

The apparatus and stimuli, which were modified versions of those used in numerous previous studies over the past 30 years, have been described elsewhere (Long \& Crambert, 1990). Landolt C targets were projected from a Kodak Ektagraphic projector (Model IIIAM) onto a front-surface mirror. The mirror, which was mounted vertically on a variable-speed turntable, reflected the target toward a $180^{\circ}$ white hemicylindrical screen positioned $1.5 \mathrm{~m}$ from the observer. For each size of Landolt $\mathrm{C}$, four target slides were prepared such that the gap in the target was located in the four diagonal positions: upper right, lower right, upper left, and lower left. The size of this critical detail in the projected Landolt $\mathrm{C}$ ranged from .63 to $32 \mathrm{~min}$ in 15 steps. The projected Landolt $\mathrm{C}$ targets were positive-contrast targets, appearing as luminous targets against the white background. A variable-speed motor controlled the rate of rotation of the turntable (and, consequently, the velocity of the projected target across the screen). Four target velocities of 60,90 , 120 , and $150 \mathrm{deg} / \mathrm{sec}$ were used, and targets always moved in a left-toright path.

Background luminance was held constant at a low photopic level of $31 \mathrm{~cd} / \mathrm{m}^{2}$. The luminance of the targets, which was controlled by positioning Kodak Wratten No. 96 neutral-density filters in front of the projector, was constant at $35 \mathrm{~cd} / \mathrm{m}^{2}$. These target and background levels were chosen on the basis of pilot work.

The observer, who wore an eyepatch over his left eye, was seated directly below the turntable with his head carefully positioned in a headand chinrest. A supporting elastic head strap held the observer's head tightly against the headrest to minimize any head movements. A Gerbrands millisecond shutter/driver system (Series 300-C), with the shutter mounted directly on the projector lens, controlled target duration (200 or $600 \mathrm{msec}$ ). The 200 -msec duration permitted a single saccadic eye movement; the 600 -msec duration allowed multiple saccades as well as extensive pursuit movements (e.g., Collewijn \& Tamminga, 1984). A verbal "ready" signal preceded target onset by approximatley $500 \mathrm{msec}$. At the outset of each trial, the observer was instructed to fixate a fixation point until the moving target appeared.

\section{Procedure}

The procedure was modified slightly from that employed by other investigators and has been used quite satisfactorily in previous published work from our laboratory (e.g., Long \& Crambert, 1990). For a given set of viewing conditions, a threshold trial run always began with a large, easily resolved Landolt $\mathrm{C}$. When the observer correctly reported the position of the gap (which varied randomly over the four positions from trial to trial), target size was reduced for the next trial. This was continued over successive trials until an incorrect response was made. At that point, the Landolt $\mathrm{C}$ was increased in size to that of the previous trial, and the trial was repeated. If correctly resolved, target size was again reduced. When the observer erred for a second time with a given target size, the trial run was stopped and the next larger size was recorded as the threshold size resolvable for that set of stimulus conditions. A new set of conditions was then introduced, and the procedure was repeated.

The first 45-min session was a practice session that served to familiarize the subject with the experimental setting and the DVA task requirements. For the remaining six sessions over a period of 2-3 weeks, three sessions were randomly selected as tobacco sessions and three as no-tobacco sessions. For the tobacco sessions, the observer was asked to use a 2.5-g dose of smokeless tobacco (Tobacco and Health Research Institute, University of Kentucky) for $30 \mathrm{~min}$ prior to data collection, while remaining in the lab room. At the end of the 30 -min period, the observer expectorated the remaining tobacco and rinsed his mouth with distilled water. Then, his resolution threshold was determined in the manner described above for the eight target conditions (two durations and four velocities) in a randomized sequence for each session. For the three no-tobacco sessions, the observer sat quietly in the lab for $30 \mathrm{~min}$ prior to the DVA determinations. All the observers were naive with respect to any experimental hypotheses.

\section{RESULTS AND DISCUSSION}

The results for each of the 6 observers are shown in Figures 1-6; Figure 7 presents the mean results for all 6 observers. In each figure, the minimum target size capable of being resolved is presented as a function of target velocity for both the tobacco and no-tobacco conditions. The two sets of curves in each figure represent the two target velocities of 200 and $600 \mathrm{msec}$. The expected effects of target velocity and target duration are quite strong. As target velocity increases, resolution threshold rises markedly; as target duration increases from 200 to $600 \mathrm{msec}$, resolution threshold drops markedly.

It should also be noted that the magnitude of the velocity effect is considerable and, at the same time, quite variable across subjects. If one examines Figure 7 , which presents the average performance of the 6 observers, the resolution thresholds even for the superior 600 -msec con-

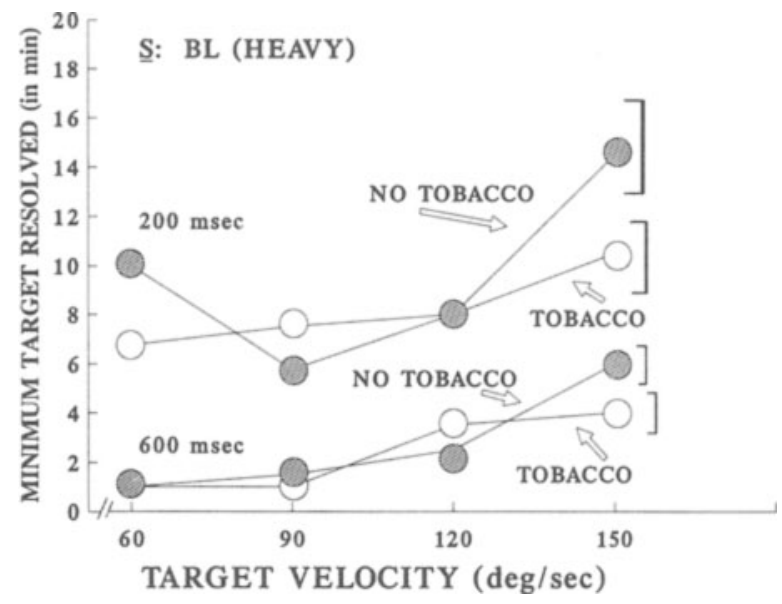

Figure 1. Threshold resolution (in minutes of arc) as a function of target velocity for both tobacco and no-tobacco conditions under 200- and 600-msec durations. The bracket at the right of each curve depicts the mean standard error for the four points comprising that curve. (Subject B.L., heavy user.) 


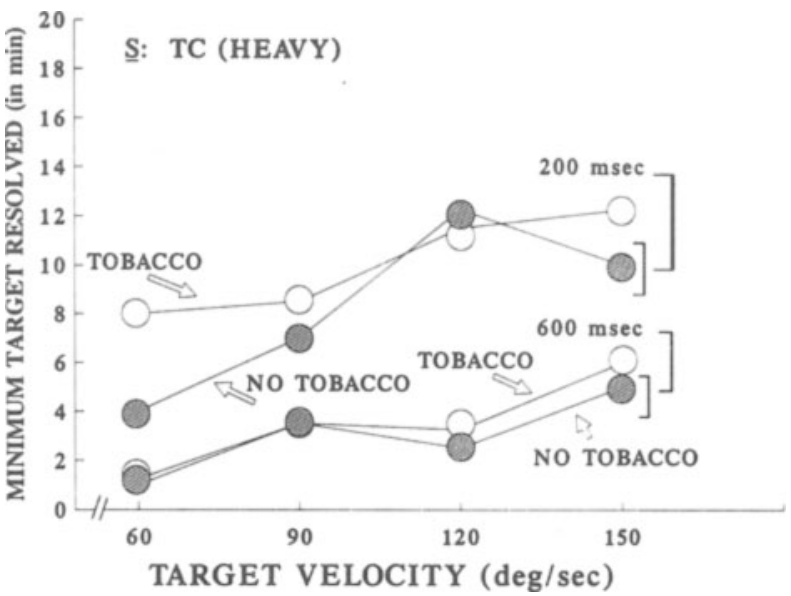

Figure 2. Threshold resolution (in minutes of arc) as a function of target velocity for both tobacco and no-tobacco conditions under 200- and 600-msec durations. The bracket at the right of each curve depicts the mean standard error for the four points comprising that curve. (Subject T.C., heavy user.)

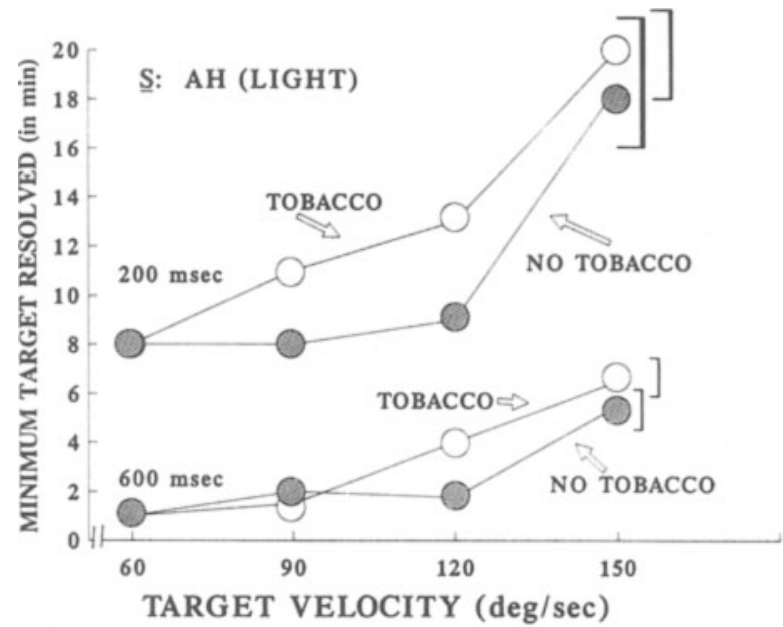

Figure 3. Threshold resolution (in minutes of arc) as a function of target velocity for both tobacco and no-tobacco conditions under 200 - and $600-$ msec durations. The bracket at the right of each curve depicts the mean standard error for the four points comprising that curve. (Subject A.H., light user.)

dition range from approximately $1.5^{\prime}$ to $5.5^{\prime}$ of arc as velocity increases from 60 to $150 \mathrm{deg} / \mathrm{sec}$. These values correspond to acuity levels of $20 / 30$ to $20 / 110$, which is not an insignificant decline in acuity for velocity conditions routinely encountered in many everyday activities.

It is also worthy of note that, for different observers, the amount of decline is much greater or much less than that depicted in the mean functions shown in Figure 7. Observers B.L. and T.C. (Figures 1 and 2) are what Miller and Ludvigh (1962) referred to as "velocity resistant" in that they exhibit rather shallow velocity-threshold functions. The other 4 observers (and particularly P.S.) are "velocity susceptible" and exhibit very steep velocity-threshold functions. Given the striking similarity of the static acuity levels for the 6 observers, the individual differences in dynamic acuity observable in Figures 1-6 further reinforce the claim that static acuity is a poor predictor of DVA performance.

It is also evident from the figures that the tobacco manipulation had no appreciable effect on DVA performance for either light or heavy tobacco users. Any apparent differences between the respective functions for a single observer are, almost without exception, within one standard error of each other; and even these small differences are not consistent across subjects. Hence, it would appear that the depiction of the tobacco effects for the group (Figure 7) is indeed representative. Quite simply, oral snuff produced no appreciable effects on DVA under any of the conditions examined.

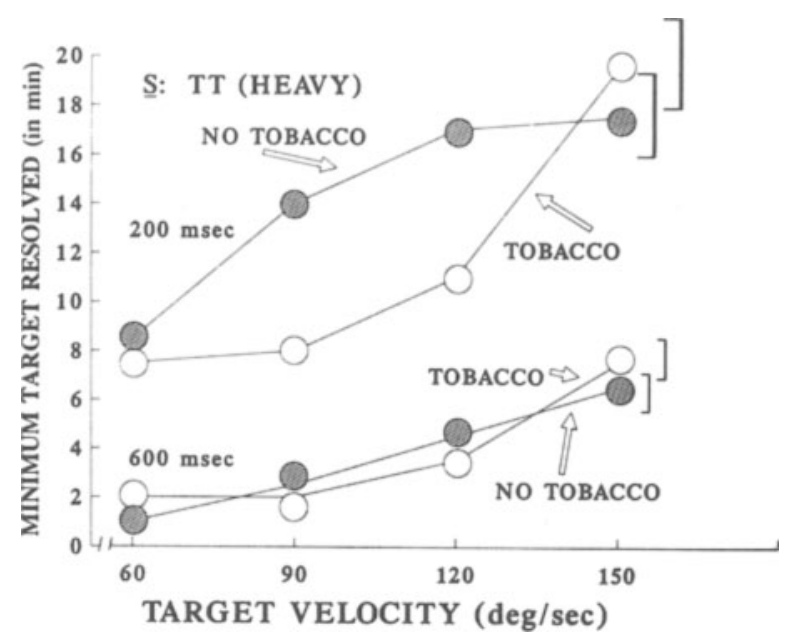

Figure 4. Threshold resolution (in minutes of arc) as a function of target velocity for both tobacco and no-tobacco conditions under 200- and 600-msec durations. The bracket at the right of each curve depicts the mean standard error for the four points comprising that curve. (Subject T.T., heavy user.)

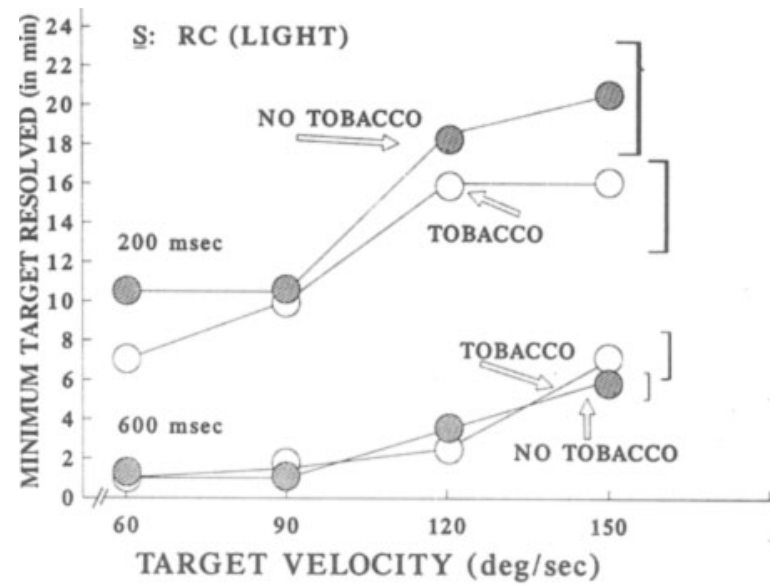

Figure 5. Threshold resolution (in minutes of arc) as a function of target velocity for both tobacco and no-tobacco conditions under 200- and 600-msec durations. The bracket at the right of each curve depicts the mean standard error for the four points comprising that curve. (Subject R.C., light user.) 


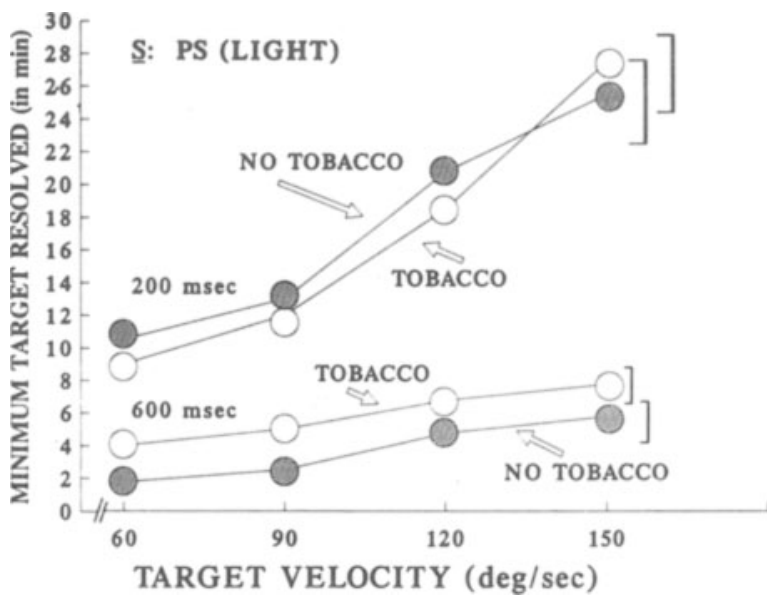

Figure 6. Threshold resolution (in minutes of arc) as a function of target velocity for both tobacco and no-tobacco conditions under 200- and 600-msec durations. The bracket at the right of each curve depicts the mean standard error for the four points comprising that curve. (Subject P.S., light user.)

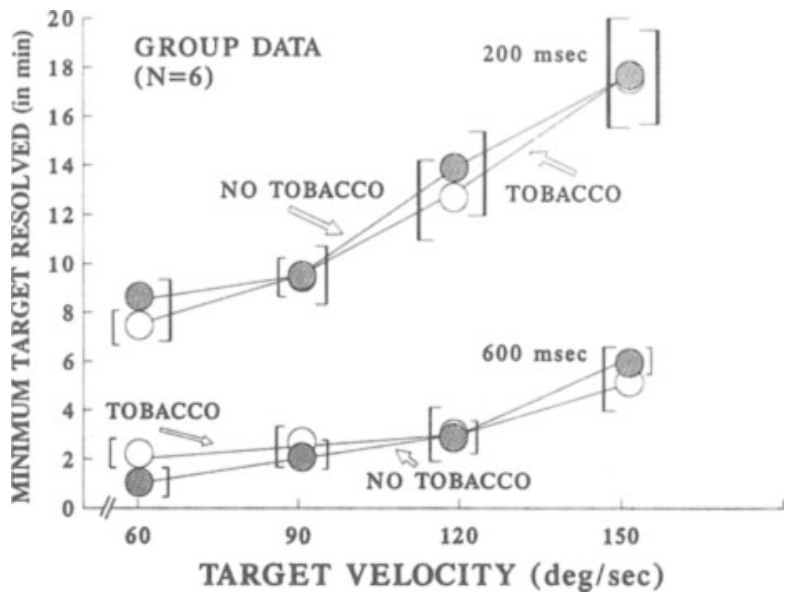

Figure 7. Mean threshold resolution (in minutes of arc) as a function of target velocity for both tobacco and no-tobacco conditions under 200- and 600-msec conditions. The brackets around each point depict one standard error above and below that mean value.

\section{SUMMARY}

In the present work, we sought to determine whether the use of oral snuff would affect DVA performance under a range of velocity and duration conditions. Although the known stimulating effect of nicotine suggested that DVA scores might be improved following tobacco use, recent reports of unusual eye movements after tobacco use suggested the distinct possibility of adverse effects on DVA. The results supported neither of these possibilities; no consistent effects of tobacco use were observed. In conjunction with previously published work, we conclude that the practical effects of nicotine use through either cigarette smoking or oral snuff on the tracking and resolution of moving targets are probably minimal.

\section{REFERENCES}

Benowitz, N. L., Porchet, H., Sheiner, L., \& Jacob, P. (1988). Nicotine absorption and cardiovascular effects with smokeless tobacco use: Comparison with cigarettes and nicotine gum. Clinical Pharmacology \& Therapeutics, 44, 23-28.

Brown, B., Adams, A. J., Haegerstrom-Portnoy, G., Jones, R. T., \& FLOM, M. C. (1975). Effects of alcohol and marijuana on dynamic visual acuity: I. Threshold measurements. Perception \& Psychophysics, 18, 441-446.

BURG, A. (1966). Visual acuity as measured by dynamic and static tests: A comparative evaluation. Joumal of Applied Psychology, 50, 460-466.

BURG, A., \& HUlBerT, S. (1961). Dynamic visual acuity as related to age, sex, and static acuity. Journal of Applied Psychology, 45, 111-116.

Collewisn, H., \& TAMmINGA, E. P. (1984). Human smooth pursuit and saccadic eye movements during voluntary pursuit of different target motions on different backgrounds. Journal of Physiology, 351, 217-250.

COMMITTEE ON VISION (1985). Emergent techniques for the assessment of visual performance. Washington, DC: National Academy Press.

DeKlerk, L. F., Eernst, J. J., \& Hoogerheide, J. (1964). The dynamic acuity of 30 selected pilots. Aeromedica Acta, 9, 129-136.

FALKowitz, C., \& MENDEL, H. (1977). The role of visual skills in batting averages. Optometric Weekly, 68, 577-580.

Fergenson, P. E., \& SuzANSKy, J. W. (1973). An investigation of dynamic and static visual acuity. Perception, 2, 343-356.

Garvey, P. M., Goebel, C. C., Tyrrell, R. A., \& Gish, K. W. (1988). Effects of alcohol consumption on contrast sensitivity for static and dynamic targets. Investigative Ophthalmology \& Vision Science, 29, 134.

Hulbert, S., Burg, A., Knoll, H. A., \& Mathewson, J. H. (1958). A preliminary study of dynamic visual acuity and its effects on motorists' vision. Journal of the American Optometric Association, 29, 359-364.

Long, G. M., \& Crambert, R. (1990). The nature and basis of agerelated changes in dynamic visual acuity. Psychology \& Aging, 5 , 138-143.

Long, G. M., \& FrankLin, M. E. (1989). The effects of smoking (nicotine nystagmus) on Dynamic Visual Acuity. Bulletin of the Psychonomic Society, 27, 163-166.

LONG, G. M. , \& GARVEY, P. M. (1988a). The effects of target borders on dynamic visual acuity: Practical and theoretical considerations. Perception, 17, 745-751.

LONG, G. M., \& GARVEY, P. M. (1988b). The effects of target color on dynamic visual acuity under photopic and scotopic viewing. Human Factors, 30, 3-14.

LoNG, G. M., \& MAY, P. A. (1992). Dynamic visual acuity and contrast sensitivity for static and flickered gratings in a college sample. Optometry \& Vision Science, 69, 915-922.

LoNG, G. M., \& RourKe, D. A. (1989). Training effects on the resolution of moving targets-dynamic visual acuity. Human Factors, 31, 443-451.

LUdVIGH, E., \& MiLleR, J. W. (1954). Some effects of training on dynamic visual acuity (NSAM-567). Pensacola, FL: Naval School of Aviation Medicine.

Miller, J. W., \& Ludvigh, E. (1962). The effect of relative motion on visual acuity. Survey of Ophthalmology, 7, 83-116.

MorRIson, T. R. (1980). A review of dynamic visual acuity (NAMRL Monograph No. 28). Pensacola, FL: Naval Aerospace Medical Research Laboratory.

Sibony, P. A., Evinger, C., \& Manning, K. A. (1987a). Effects of tobacco on pursuit eye movements and blinks. Investigative Ophthalmology \& Vision Science, 28, 316.

Sibony, P. A., Evinger, C., \& Manning, K. A. (1987b). Tobaccoinduced primary-position upbeat nystagmus. Annals of Neurology, 21, 53-58.

SURGEON GENERAL'S REPORT (1986). The health consequences of using smokeless tobacco: A report of the Advisory Committee to the Surgeon General. Bethesda, MD: U.S. Department of Health \& Human Services. 